\title{
Reason for Denial
}

National Cancer Institute

\section{Source}

National Cancer Institute. Reason for Denial. NCI Thesaurus. Code C99674.

The explanation why a particular action was rejected or denied. 